\title{
Crystallization of Mixed Alkaline-Earth Carbonates in Silica Solutions at High $\mathrm{pH}$
}

\author{
Josef Eiblmeier, ${ }^{\dagger}$ Stephan Dankesreiter, ${ }^{\ddagger}$ Arno Pfitzner, ${ }^{\ddagger}$ Gottfried Schmalz, ${ }^{\S}$ Werner Kunz, ${ }^{\dagger}$ \\ and Matthias Kellermeier*, ${ }^{\dagger}, \perp$ \\ ${ }^{\dagger}$ Institute of Physical and Theoretical Chemistry, University of Regensburg, Universitätsstraße 31, D-93040 Regensburg, Germany \\ ${ }^{\ddagger}$ Institute of Inorganic Chemistry, University of Regensburg, Universitätsstraße 31, D-93040 Regensburg, Germany \\ ${ }^{\S}$ Department of Operative Dentistry and Periodontology, University of Regensburg, Franz-Josef-Strauss-Allee 11, D-93053 \\ Regensburg, Germany
}

\section{Supporting Information}

\begin{abstract}
The ability of silica to influence the mineralization of alkaline-earth carbonates is an outstanding example for the formation of biomimetic structures in the absence of any organic matter. Under suitable conditions, silica-stabilized carbonate nanocrystals can spontaneously self-assemble into hierarchical materials with complex morphologies, commonly referred to as "silica biomorphs". However, growth of these crystal aggregates has largely been restricted to the higher homologues in the alkaline-earth series, i.e., $\mathrm{SrCO}_{3}$ and $\mathrm{BaCO}_{3}$, while corresponding architectures of the much more relevant calcium carbonate are quite difficult to realize. To systematically address this problem, we have crystallized metal carbonates in the presence of silica at high $\mathrm{pH}$, using barium and strontium chloride solutions that contained increasing molar fractions of $\mathrm{Ca}^{2+}$. The resulting materials were analyzed with respect to their composition, structure, and

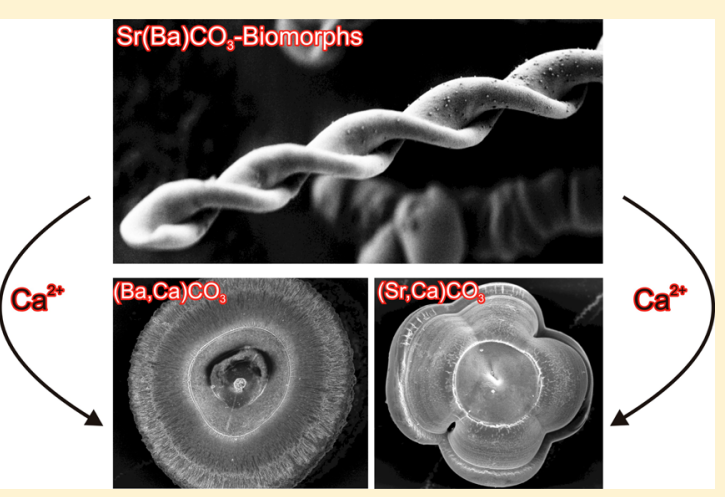
crystallography. The obtained data demonstrate that the growth process is already strongly affected by small amounts of calcium. Indeed, morphologies typically observed for $\mathrm{SrCO}_{3}$ and $\mathrm{BaCO}_{3}$ remained absent above certain thresholds of added $\mathrm{Ca}^{2+}$. Instead, globular and hemispherical structures were generated, owing to fractal branching of carbonate crystals as a consequence of poisoning by silica. These alterations in the growth behavior are ascribed to relatively strong interactions of hard calcium ions with silicate species in solution, shifting their speciation toward higher oligomers and even inducing partial coagulation. This notion is confirmed by additional experiments at increased ionic strength. Our results further demonstrate that the observed hemispherical particles exhibit distinct polymorphism, with orthorhombic solid solutions (aragonite-type $(\mathrm{Sr}, \mathrm{Ca}) \mathrm{CO}_{3}$ and $\left.(\mathrm{Ba}, \mathrm{Ca}) \mathrm{CO}_{3}\right)$ being formed at lower $\mathrm{Ca}^{2+}$ contents, whereas $\mathrm{Sr}^{2+} / \mathrm{Ba}^{2+}$-substituted calcite prevails at higher $\mathrm{Ca}^{2+}$ fractions. In the case of $\mathrm{Ba}^{2+} / \mathrm{Ca}^{2+}$ mixtures, there is moreover an intermediate range where virtually identical morphologies were confirmed to be $\mathrm{Ba}^{2+}$-doped vaterite. These findings extend the variety of structures and compositions accessible in these simple systems, and may explain difficulties previously encountered in attempts to prepare $\mathrm{CaCO}_{3}$ biomorphs at standard conditions.
\end{abstract}

\section{INTRODUCTION}

In the past decades, the demand for new materials with specific properties has drastically increased. Modern synthetic approaches often follow strategies relying on bottom-up selfassembly of rather simple and cheap educts. ${ }^{1-4}$ In this context, so-called "silica biomorphs" have attracted growing attention, as these mesoscopically ordered architectures develop spontaneously from purely inorganic precursors via concerted interactions of the involved components. ${ }^{5-19}$ Biomorphs consist of alkaline-earth carbonate (usually $\mathrm{BaCO}_{3}$ ) nanorods, which are stabilized and interwoven by amorphous silica, and build up complex crystal aggregates that resemble biogenic minerals. Moreover, they display a broad variety of noncrystallographic morphologies, ranging from flat sheets over helicoids to coral- or worm-like structures. ${ }^{5,6,16,19-21}$
Recently, considerable progress has been made toward an understanding of the mechanisms leading to morphogenesis on the micrometer level, as well as the driving forces governing particle-based crystallization at the nanoscale. ${ }^{12,13,16,19,22}$ In essence, a scenario was proposed that segments the growth process into two principal stages: all characteristic architectures arise from a micrometer-sized carbonate crystal seed, which nucleates heterogeneously after some delay and soon adopts an elongated pseudohexagonal habit typical for orthorhombic carbonates. ${ }^{14,16,23}$ Upon further growth, this crystal starts to split at both ends along the $c$-axis due to nonspecific poisoning

Received: March 24, 2014

Revised: August 20, 2014

Published: October 23, 2014 
by oligomeric silicate species, leading to tilted outgrowths at noncrystallographic angles. Branching occurs mainly through the basal (001) faces and, after self-similar (fractal) propagation, yields increasingly bifurcated particles that develop through dumbbell-shaped forms eventually into closed spherulites or spacious cauliflower-like structures. ${ }^{6,13,14,16,20}$ From a morphological point of view, this growth behavior is similar to what has been observed for fluorapatite crystallization in gelatin matrices. ${ }^{24-26}$ In a subsequent second stage, fractal branching gives way to polycrystalline mineralization, where silica-sheathed carbonate nanoparticles are constantly nucleated and serve as building blocks for the construction of biomorphic aggregates, which then evolve free from symmetry constraints toward complex curved morphologies. The continuous production of nanocrystal units is explained by local variations of $\mathrm{pH}$ and supersaturation nearby the front of the aggregates, as a consequence of the inverse trends in solubility of silica and carbonate with $\mathrm{pH}$ in alkaline media: growth of carbonate particles causes a decrease of $\mathrm{pH}$ in their vicinity (due to bicarbonate dissociation), which leads to local precipitation of silica and stabilization of the crystallites. ${ }^{13,17}$ Ongoing silica condensation then re-increases the $\mathrm{pH}$ at the front, so that a novel event of carbonate nucleation is induced and the previous steps are reiterated. Thus, the mineralization of the two components is coupled via the local $\mathrm{pH}$, resulting in alternating precipitation through autocatalytic processes. ${ }^{12,13,22}$ However, this dynamic interplay only occurs within a certain range of conditions, as determined by parameters like the bulk $\mathrm{pH},{ }^{14,27}$ and recent studies also demonstrated that the final morphologies displayed by silica biomorphs may strongly depend on subtle factors. ${ }^{15,16,19,21,28}$

Another mandatory requirement for the formation of true silica biomorphs (i.e., nanocrystalline aggregates exhibiting sinuous shapes) seems to be the use of carbonates that crystallize in an orthorhombic structure, such as strontianite $\left(\mathrm{SrCO}_{3}\right)$ and witherite $\left(\mathrm{BaCO}_{3}\right.$; both being isotypic with the $\mathrm{CaCO}_{3}$ polymorph aragonite). In fact, $\mathrm{Ba}^{2+}$ and $\mathrm{Sr}^{2+}$ salts can be mixed at arbitrary ratios without any change in the morphologies of the resulting biomorphs, which suggests that both metal ions are homogeneously distributed within the mature aggregates. ${ }^{9}$ Calcium carbonate-by far the most abundant mineral within the alkaline-earth series and of high relevance for industrial processes-also forms biomimetic structures in silica-rich environments. ${ }^{29-31}$ However, these precipitates usually consist of rhombohedral calcite (the stable modification at ambient conditions) and do not display intricate curved morphologies as those being characteristic for biomorphs (like worms or helicoids). Actual $\mathrm{CaCO}_{3}$ biomorphs were in turn produced by tuning synthesis parameters in order to shift polymorph selection in the direction of aragonite. This was successfully accomplished by increasing the temperature to $80^{\circ} \mathrm{C}$, thus kinetically favoring the formation of aragonite, ${ }^{21}$ or by using suitable seed crystals. ${ }^{32}$ In this context, it is worth mentioning that calcium carbonate structures with comparable shape and complexity (e.g., spirals) have also been generated in the presence of polyelectrolytes like poly(acrylic acid) or poly(aspartic acid), where the (organic) polymers induce liquid-like mineral precursors that may yield nonequilibrium morphologies upon solidification. ${ }^{33}$ Clearly, it would be desirable to develop a bottom-up protocol allowing for the preparation of $\mathrm{CaCO}_{3}$ biomorphs at room temperature, without the need for external triggers like seeds. Preliminary observations made in very recent work have indicated that silica-aragonite biomorphs might indeed grow spontaneously in silica gels under very particular conditions (i.e., specific concentrations, $\mathrm{pH}$, location in the gel, etc.). ${ }^{34}$ However, detailed insight into the role of the different parameters and control over the final structures has not yet been gained.

Another potential way to generate $\mathrm{CaCO}_{3}$ biomorphs at room temperature is to work with mixtures of calcium and barium or strontium, as it is known that both witherite and strontianite can incorporate $\mathrm{Ca}^{2+}$ into their crystal lattice (forming solid solutions), ${ }^{35-37}$ and that even minor amounts of the larger $\mathrm{Ba}^{2+}$ or $\mathrm{Sr}^{2+}$ ions can force calcium carbonate into the aragonite modification. ${ }^{38}$ Here, we have investigated the possibility of growing silica-aragonite biomorphs by crystallizing carbonates from mixtures of $\mathrm{BaCl}_{2}$ or $\mathrm{SrCl}_{2}$ and $\mathrm{CaCl}_{2}$ under the influence of dissolved silica at high $\mathrm{pH}$. To that end, we performed experiments in which the ratio of $\mathrm{Ba}^{2+} / \mathrm{Sr}^{2+}$ to $\mathrm{Ca}^{2+}$ was systematically varied, at overall constant metal ion concentration. The resulting precipitates were investigated in terms of morphology, composition and structure, focusing on the specific influence of the divalent calcium ions on morphogenesis.

\section{EXPERIMENTAL SECTION}

2.1. Materials. Barium chloride dihydrate (Sigma-Aldrich, $\geq 99 \%$ ), strontium chloride hexahydrate (Sigma-Aldrich, ACS reagent, $\geq 99 \%$ ), and calcium chloride dihydrate (Riedel-de Haën, ACS reagent, $\geq 99 \%$ ) were used as received. The silica source was a commercially available water glass stock (Sigma-Aldrich, reagent grade, containing ca. $13.7 \mathrm{wt}$ $\% \mathrm{NaOH}$ and $12.5 \mathrm{wt} \% \mathrm{Si}$ ). All solutions and dilutions were prepared with water of Milli-Q quality and stored in tightly stoppered plastic bottles, to prevent silica contamination from glass walls and uncontrolled uptake of atmospheric $\mathrm{CO}_{2}$.

2.2. Crystallization Experiments. Growth of alkaline-earth carbonates in the presence of silica was carried out in stagnant solutions, following similar procedures as in previous studies. ${ }^{6,12,14,23,28}$ First, the silica stock was diluted with water by a factor of $1: 350(\mathrm{v} / \mathrm{v})$ and then mixed at a ratio of 20:1 ( $/ \mathrm{v})$ with $0.1 \mathrm{M}$ sodium hydroxide (Merck, p.a.). Crystallization was initiated by combining $5 \mathrm{~mL}$ of the resulting silica sol $(\mathrm{pH} \sim 11.3)$ with the same volume of $0.01 \mathrm{M}$ metal chloride solutions containing different molar fractions of $\mathrm{CaCl}_{2}\left(x_{\mathrm{Ca}}=\right.$ $0,0.02,0.10,0.20,0.50,0.80$, and 1.00) next to either $\mathrm{BaCl}_{2}$ or $\mathrm{SrCl}_{2}$. Experiments were conducted at $20 \pm 1{ }^{\circ} \mathrm{C}$ in sterile 6-well microplates (Nunclon, polystyrene, $10 \mathrm{~mL}$ total volume, $9.6 \mathrm{~cm}^{2}$ bottom area, 1.7 $\mathrm{cm}$ in depth). Glass coverslips $(22 \times 22 \mathrm{~mm})$ were placed as growth substrates on the bottom of the well before filling with growth solution (thus crystals were formed only on the top side of the substrate). After exposure of the samples to the atmosphere over predefined periods (varying between $18 \mathrm{~h}$ and 3 days and depending on the $\mathrm{Ca}^{2+}$ content), the substrates were removed with a pair of tweezers and subsequently washed with water and ethanol (Baker, p.a.), followed by drying in air.

2.3. Characterization Methods. First, the time-dependent macroscopic behavior of the samples at distinct barium/strontium:calcium ratios was observed visually. To that end, time-lapsed series of photographs were recorded with a remote-controlled Canon EOS $350 \mathrm{D}$ digital camera. The $\mathrm{pH}$ of the samples was measured directly after combining reagents (i.e., the metal salt mixture with the silica sol) and after a period of $24 \mathrm{~h}$ by means of a polymer-based electrode (Mettler-Toledo, InLab Expert), which was connected to a Schott CG843 laboratory $\mathrm{pH}$ meter. The initial $\mathrm{pH}$ was found to be $11.0 \pm 0.1$, independent of the $\mathrm{CaCl}_{2}$ content and whether $\mathrm{Ba}^{2+}$ or $\mathrm{Sr}^{2+}$ was used, which is in good agreement with values reported for pure $\mathrm{Ba}^{2+}$ systems in previous work. ${ }^{14,23}$ Within 1 day, the $\mathrm{pH}$ decreased to $9.6 \pm 0.1$ in all samples due to in-diffusion of $\mathrm{CO}_{2}$ into the alkaline solutions, forming carbonic acid which rapidly deprotonates to give carbonate and bicarbonate species. 


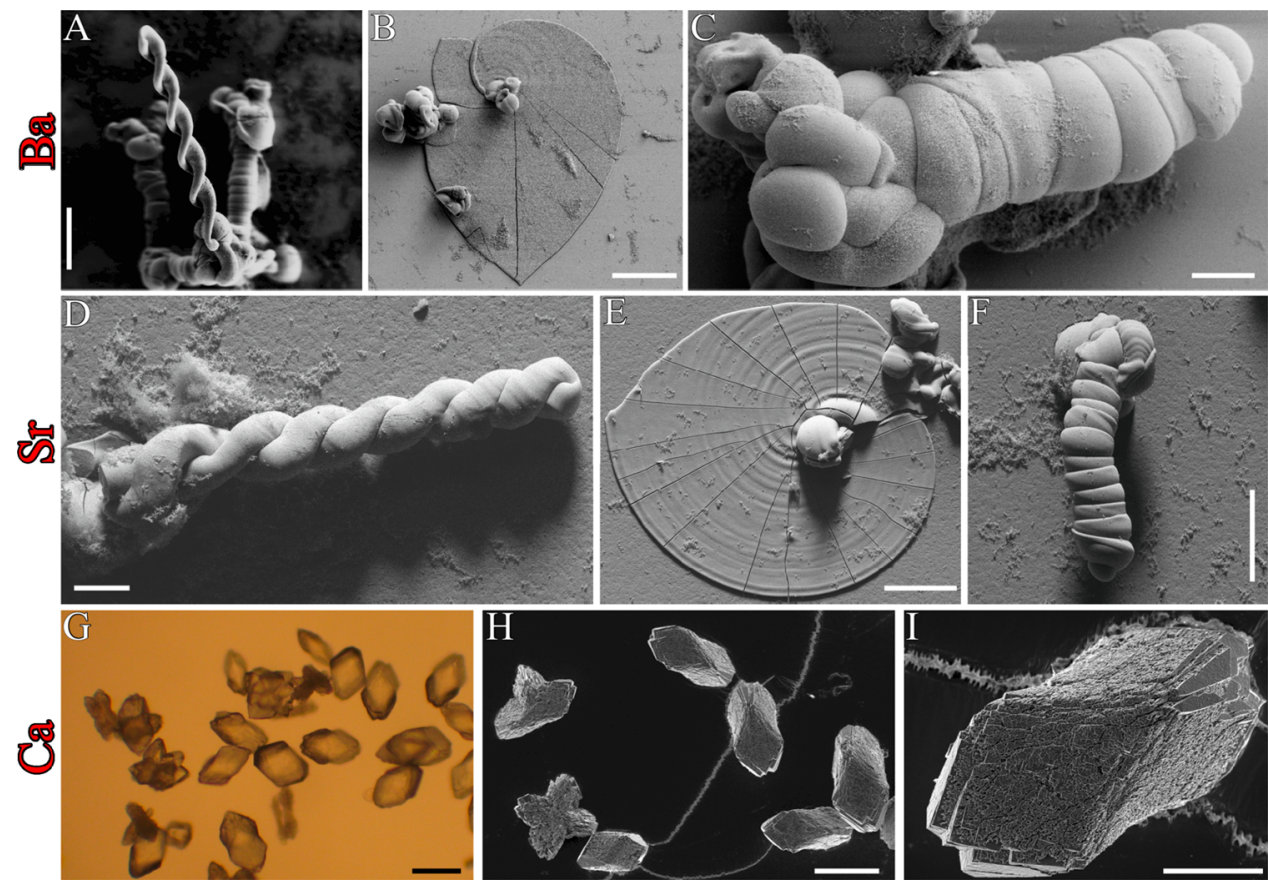

Figure 1. FESEM (A-F, H, and I) and optical (G) micrographs of $\mathrm{BaCO}_{3}$ (upper panels), $\mathrm{SrCO}_{3}$ (middle panels), and CaCO (lower panels) structures formed upon precipitation from silica-containing solutions at high $\mathrm{pH}$. (A-C) Silica-witherite biomorphs, showing helicoidal filaments (A), flat sheets (B), and worms (C) as main morphologies. (D-E) Silica-strontianite biomorphs, virtually indistinguishable from their $\mathrm{BaCO}_{3}$ counterparts. (G-I) Unusual calcite crystals, elongated along their $c$-axis and exhibiting dome-like outgrowths. Scale bars: $(A, B) 50 \mu \mathrm{m},(C) 10 \mu \mathrm{m}$, (D) $20 \mu \mathrm{m},(\mathrm{E}-\mathrm{H}) 50 \mu \mathrm{m}$, and (I) $20 \mu \mathrm{m}$.

Isolated precipitates were routinely studied by polarized optical microscopy using a Nikon Eclipse E400 transmission microscope, onto which a Canon EOS 350D camera was mounted for imaging. For scanning electron microscopy (SEM), aggregates were grown directly on a conducting foil, which was placed on the bottom of the wells as a growth substrate. After careful rinsing with water and ethanol, the foil carrying the precipitates was mounted directly on the SEM stub and coated with a thin gold layer. Specimens were investigated with a Zeiss LEO Gemini 1530 or a FEI Quanta $400 \mathrm{~T}$ microscope, at acceleration voltages ranging from 3 to $10 \mathrm{kV}$. Energy-dispersive X-ray (EDX) spectroscopy measurements were carried out at $10 \mathrm{kV}$ with the help of an installed Oxford INCA microanalysis system. Spectra were recorded at three different positions on the stub, in order to average results for a given sample. X-ray diffraction (XRD) data were recorded on a STOE STADI $\mathrm{P}$ diffractometer using $\mathrm{Cu} \mathrm{K} \alpha_{1}$ radiation and a germanium single-crystal monochromator $(\lambda=1.540598 \AA$ \&). Patterns were acquired over a $2 \theta$ range of $8^{\circ}-90^{\circ}$ at a scanning speed of $0.8^{\circ} \%$ min. Dynamic light scattering (DLS) experiments were performed with a CGS-3 goniometer system from ALV (Langen, Germany), which was equipped with an ALV-7004/FAST Multiple Tau digital correlator and a $\mathrm{He}-\mathrm{Ne}$ laser operating at a wavelength of $638.2 \mathrm{~nm}$. Equal volumes of $10 \mathrm{mM}$ metal chloride solution $\left(x_{\mathrm{Ca}}=0.02\right)$ and the silica sol were first passed through syringe filters (VWR, cellulose acetate, $200 \mathrm{~nm}$ ) and subsequently combined in a vial. Next, $1.5 \mathrm{~mL}$ of the resulting mixture was transferred into a DLS cuvette, and measurements were started $20 \mathrm{~s}$ after mixing. The temporal evolution of particle size was traced over the following $30 \mathrm{~min}$ by performing consecutive runs of $60 \mathrm{~s}$ duration each. The average size of the scattering species was calculated by fitting monomodal equations to the experimental correlation functions.

\section{RESULTS}

3.1. Morphological Analysis. 3.1.1. Reference Experiments. First, reference experiments were performed in which witherite and strontianite were crystallized in the absence of $\mathrm{Ca}^{2+}$ under conditions commonly applied for the synthesis of silica biomorphs $\left(5 \mathrm{mM} \mathrm{Ba}^{2+}\right.$ or $\left.\mathrm{Sr}^{2+}, 8.4 \mathrm{mM} \mathrm{SiO}_{2}, \mathrm{pH} \sim 11\right)$. The resulting aggregates exhibited morphologies very similar to those reported previously, ${ }^{5-8,11,14,15,23,34}$ without any significant morphological or structural differences between $\mathrm{BaCO}_{3}$ and $\mathrm{SrCO}_{3}$. Typical forms include regular helicoids, flat leaf-like sheets, as well as thicker and more tightly wound worms (Figure 1A-F).

Along with these complex polycrystalline structures, various fractal aggregates-globules, dumbbells, and clusters thereofwith diameters around $10 \mu \mathrm{m}$ were frequently observed (Figure 2), all of which arise from splitting of an initial rod-like carbonate seed crystal, as described above and explained in detail elsewhere. ${ }^{6,13,16}$ Bottom views reveal that bifurcation of the core crystal occurs along the [001] direction (Figure 2C), and that progressive branching first yields dumbbell-like particles (Figure 2A), which finally become closed to give spherulithic architectures (Figure 2B,D). These fractal structures are known to be precursors of the more characteristic noncrystallographic morphologies displayed by silica biomorphs. ${ }^{6,13,16}$ After some time, laminar domains (composed of silica-stabilized nanocrystals) start to sprout radially from the globular units and subsequently grow flat in a nearly twodimensional manner into extended sheet-like objects (Figure $1 \mathrm{~B}, \mathrm{E}$, with the initial fractal clusters being visible in the center of the leaves). The more elaborate, curved ultrastructures (helicoids and worms, cf. Figure $1 \mathrm{~A}, \mathrm{C}, \mathrm{D}, \mathrm{F}$ ) in turn emerge when sheets become curled at their rim and distinct segments begin to wind around one another; parameters determining the final shape of these twisted aggregates have been thoroughly discussed in the literature. ${ }^{13,22,23}$

When crystallization was carried out under the same conditions but using $5 \mathrm{mM} \mathrm{CaCl}$ instead of $\mathrm{BaCl}_{2} / \mathrm{SrCl}_{2}$, the solutions became turbid several minutes after mixing of reagents (see Figure S1 in the Supporting Information (SI)), 

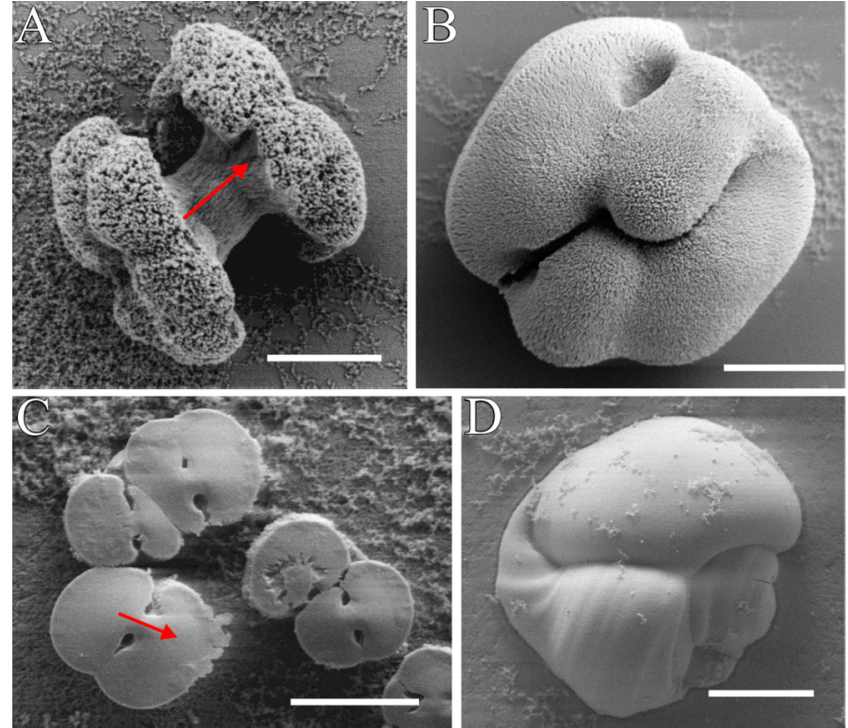

Figure 2. Fractal architectures of $(\mathrm{A}, \mathrm{B}) \mathrm{BaCO}_{3}$ and $(\mathrm{B}, \mathrm{C}) \mathrm{SrCO}_{3}$, produced by continuous branching of an initial seed crystal along its $c$ axis (indicated by arrows), at first yielding dumbbell-like morphologies $(A, C)$, which then develop into more or less closed spherulites $(B, D)$. Note that these structures are precursors of the curved forms generated during the second stage of biomorph growth (however, not all of these particles give rise to characteristic polycrystalline aggregates, so some of them remain as "byproduct"). Scale bars: (A) $2 \mu \mathrm{m}$, (B) $5 \mu \mathrm{m}$, (C) $10 \mu \mathrm{m}$, and (D) $20 \mu \mathrm{m}$.

in contrast to the previous experiments with $\mathrm{Ba}^{2+}$ and $\mathrm{Sr}^{2+}$. This can be ascribed to stronger interactions of the hard calcium ions with negatively charged silicate species existing in solution at high $\mathrm{pH}^{39}$ Thereby, the divalent cations screen the charges and provoke polymerization of silica, causing coagulation and the deposition of a layer of silica gel on the bottom of the well. Within this layer, crystals with extraordinary shapes and fairly uniform dimensions (ca. $50 \mu \mathrm{m}$ ) grew within a period of about 3 days (Figure $1 \mathrm{G}-\mathrm{I}$ ), and were confirmed to be calcite by XRD (cf. Figure 6, below).

Closer examination suggests that these crystals are elongated along the crystallographic $c$-axis and consist of micrometersized, tabular subunits. Moreover, they display large dome-like outgrowths on one of their ends (Figure 1I). Similar morphologies and structures have been obtained previously by crystallization of $\mathrm{CaCO}_{3}$ in silica gels upon in-diffusion of $\mathrm{CaCl}_{2},{ }^{30,34}$ and were also observed during growth from solution at high supersaturation. ${ }^{29}$ Taken together, it is obvious that $\mathrm{Ba}^{2+}$ and $\mathrm{Sr}^{2+}$ readily form biomorphs at ambient conditions, whereas $\mathrm{Ca}^{2+}$ "only" gives complex single crystals and/or mesocrystals. We now turn to consider changes in the growth behavior traced when gradually replacing $\mathrm{Ba}^{2+} / \mathrm{Sr}^{2+}$ by $\mathrm{Ca}^{2+}$.

3.1.2. Effect of Added $\mathrm{Ca}^{2+}$ on the Growth Behavior of Silica-Witherite Biomorphs. Introducing $\mathrm{Ca}^{2+}$ to the mother solution of $\mathrm{BaCO}_{3}$ biomorphs proved to have a strong influence on the morphology of resulting precipitates. Visual observations show that for calcium molar fractions equal to or higher than 0.20 , the samples become turbid soon after mixing (see Figure $\mathrm{S} 1$ in the $\mathrm{SI})$, as in the case of the reference experiments with pure $\mathrm{CaCl}_{2}$, thus indicating significant $\mathrm{Ca}^{2+}$-induced silica condensation also at lower cation concentrations. Again, crystallization occurred exclusively within the gel domains formed after some delay due to ongoing silica polymerization. Furthermore, the time required for crystals to be observed (ca. 3 days) was considerably longer than in the absence of $\mathrm{Ca}^{2+}$
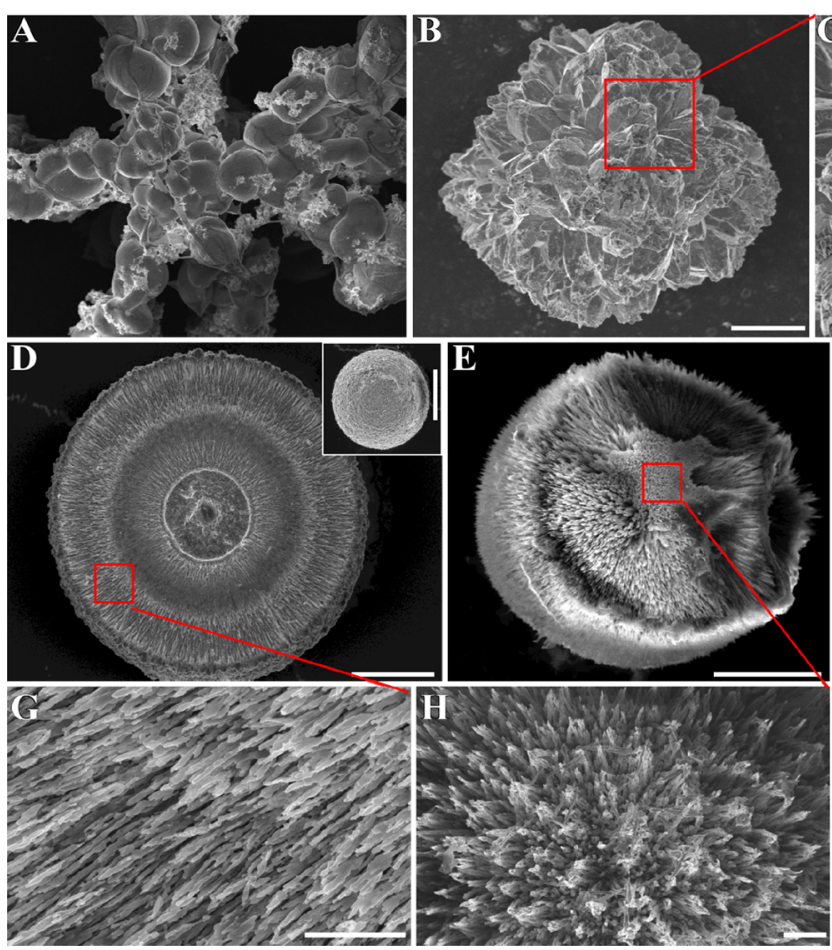
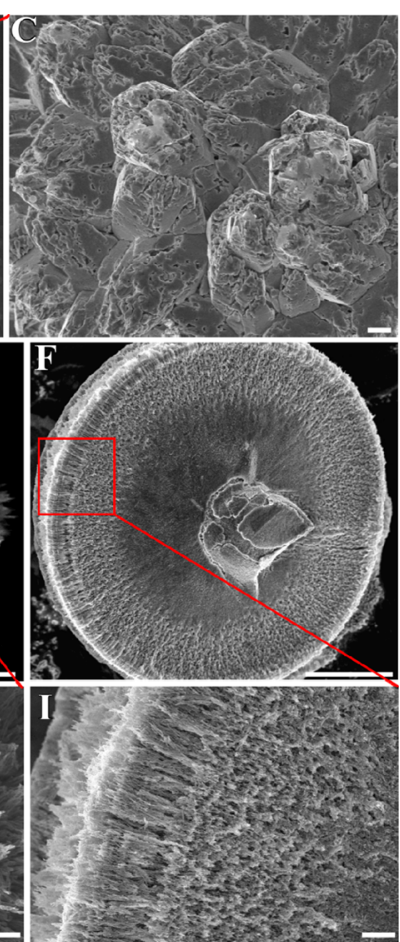

Figure 3. FESEM images of fractal crystal aggregates grown from silica-containing mixtures of $\mathrm{Ba}^{2+}$ and $\mathrm{Ca}^{2+}$ at calcium molar fractions of $(\mathrm{A}) 0.02$, $(\mathrm{B}, \mathrm{C})$ 0.10, $(\mathrm{D}, \mathrm{G})$ 0.20, $(\mathrm{E}, \mathrm{H})$ 0.50, and $(\mathrm{F}, \mathrm{I})$ 0.80. (C,G-I) Close-up views of the precipitates formed at distinct $\mathrm{Ca}^{2+}$ contents, revealing their microstructure. Increasing the calcium concentration first results in fairly large assemblies of blocky subunits (B), before nearly perfect (hemi)spherical structures are obtained at higher $\mathrm{Ca}^{2+}$ fractions (D-F). Scale bars: (A-F) $20 \mu \mathrm{m}$, (inset of D) $50 \mu \mathrm{m}$, and (C,G-I) $2 \mu \mathrm{m}$. 


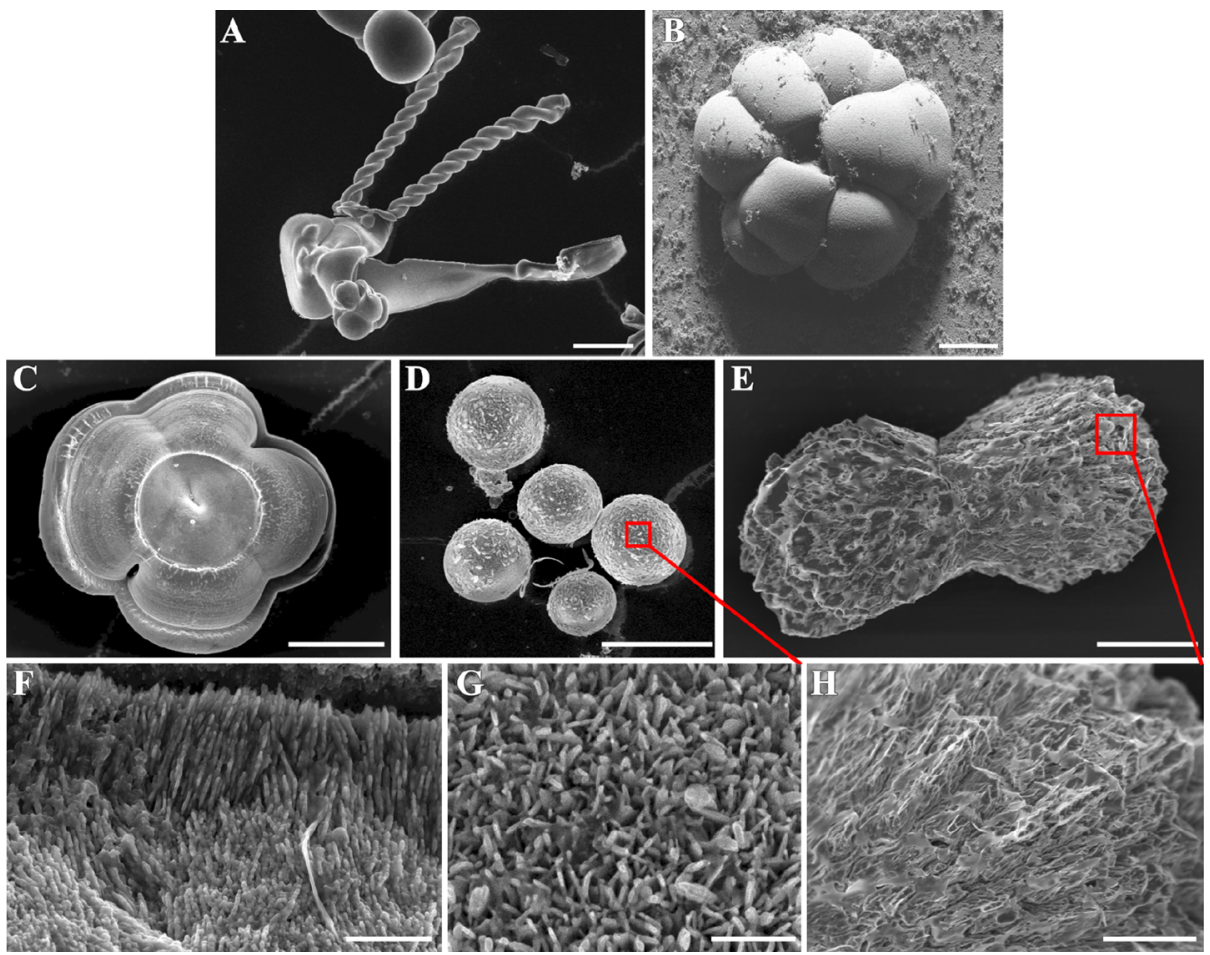

Figure 4. FESEM images of aggregates formed upon carbonate crystallization from mixtures of $\mathrm{SrCl}_{2}$ and $\mathrm{CaCl}_{2}$ under the influence of silica at high $\mathrm{pH}$. The respective molar fraction of $\mathrm{Ca}^{2+}$ in the mother solutions was varied as follows: (A) 0.02, (B) 0.10, (C) 0.20, (D) 0.50, and (E) 0.80. While biomorphs are still observed at low calcium content $(\mathrm{A})$, only fractal structures (either spherical or raspberry-shaped) were obtained for $0.10 \leq x_{\mathrm{Ca}} \leq$ $0.50(\mathrm{~B}-\mathrm{D})$. In the presence of excess $\mathrm{Ca}^{2+}\left(x_{\mathrm{Ca}}=0.80\right)$, crystals displaying elongated habits and consisting of multiple fibrous projections (E) represent the main morphology. $(\mathrm{F}-\mathrm{H})$ Higher magnifications of the precipitates shown in $(\mathrm{C}-\mathrm{E})$, providing insight into structural details. Scale bars: (A-E) $50 \mu \mathrm{m},(\mathrm{F}, \mathrm{G}) 1 \mu \mathrm{m}$, and $(\mathrm{H}) 10 \mu \mathrm{m}$.

$(<10 \mathrm{~h})$, and also the absolute number of particles was found to decrease with increasing $x_{\mathrm{Ca}}$. Figure 3 illustrates the morphological evolution observed for mixtures of $\mathrm{BaCl}_{2}$ and $\mathrm{CaCl}_{2}$ at different molar fractions of $\mathrm{Ca}^{2+}$. Drastic changes in the distribution of morphologies can be discerned already at calcium molar fractions as low as 0.02 (Figure 3A). In fact, there was not a single characteristic biomorph occurring throughout a series of syntheses at these conditions. Instead, fairly large conglomerates (up to $300 \mu \mathrm{m}$ ) of multiple intergrown fractal spherulites were observed. Individual units closely resemble those formed in $\mathrm{Ca}^{2+}$-free experiments (cf. Figure 2), which suggests that the self-similar branching process (i.e., the first stage of morphogenesis) is not noticeably affected by the $\mathrm{Ca}^{2+}$ ions. On the other hand, the fact that biomorphic ultrastructures were not at all formed indicates that the second stage of morphogenesis-i.e., coupled co-mineralization of silica and carbonate and their assembly into curved nanocrystalline aggregates - cannot be initiated even in the presence of only small amounts of calcium ions.

At a $\mathrm{Ca}^{2+}$ fraction of 0.10 , we could again only distinguish spherulitic objects, however with quite distinct appearance. Indeed, the observed crystal architectures consisted of rather thick, blocky subunits with widths in the range of $5 \mu \mathrm{m}$, which were arranged radially outward from a common origin (Figure 3B,C). Single subunits are identified as cyclic witherite twins, in which twinning occurs through the (110) planes. ${ }^{37}$ Evidently, branching is less pronounced here than in the reference experiments without $\mathrm{Ca}^{2+}$ (Figure 2) and at lower $x_{\mathrm{Ca}}$ (Figure $3 \mathrm{~A})$, leading to structures with much smaller fractal dimensionality and larger subunits.
When the calcium content is further increased to 0.20 and 0.50 (Figure 3D,E), almost perfectly spheroidal aggregates with diameters of around $100 \mu \mathrm{m}$ are obtained. Zooms onto the surface of the precipitates reveal ordered fiber-like subunits (Figure 3G,H) that emanate radially from the growth center and are about $1 \mu \mathrm{m}$ wide, suggesting a high degree of fractal branching. Widely identical morphologies and textures were also observed when the amount of $\mathrm{Ca}^{2+}$ exceeded that of $\mathrm{Ba}^{2+}$ in the mixtures (i.e., at $x_{\mathrm{Ca}}=0.80$, Figure $3 \mathrm{~F}, \mathrm{I}$ ). Bottom views of these structures further confirm the radial arrangement of the building units and moreover show that they are in fact hemispheres with an entirely flat bottom side (cf. Figure 3D,F). This indicates that the original crystal seed was nucleated heterogeneously at the walls of the vessel and subsequently continued growing in direct contact with the interface, as in the case of the fractal precursors found in the reference experiments without $\mathrm{Ca}^{2+}$ (cf. Figure 2B,D). However, in contrast to the latter, the core crystal did not attach to the walls via its lateral faces, but rather through its basal one (see below). Another main difference is that the hemispheres produced at these $\mathrm{Ca} / \mathrm{Ba}$ ratios are considerably larger than the globules formed in the absence of calcium ions (100 $\mu \mathrm{m}$ vs $10 \mu \mathrm{m})$.

3.1.3. Effect of Added $\mathrm{Ca}^{2+}$ on the Growth Behavior of Silica-Strontianite Biomorphs. Gradual replacement of $\mathrm{Sr}^{2+}$ by $\mathrm{Ca}^{2+}$ also led to clouding of the solutions after a certain induction period (up to about $1 \mathrm{~h}$ depending on the calcium concentration, cf. Figure S1 in the SI) and, for $x_{\mathrm{Ca}} \geq 0.20$, resulted in the formation of a gel carpet on the bottom of the wells, where crystallization took place in the following. Typical morphologies observed as a function of increasing calcium content are illustrated in Figure 4. Unlike the experiments 
performed with mixtures of $\mathrm{BaCl}_{2}$ and $\mathrm{CaCl}_{2}$ (Figure 3), characteristic biomorphic aggregates like regular helicoids (Figure 4A) or worm-like braids (not shown) still occurred in the presence of $2 \mathrm{~mol} \% \mathrm{Ca}^{2+}$. However, these structures were less frequent and seemed to be less developed as compared to counterparts grown from calcium-free solutions. At a $\mathrm{Ca}^{2+}$ molar fraction of 0.10 , merely clusters of interpenetrating globular units with sizes of about $200 \mu \mathrm{m}$ were observed (Figure 4B), whereas twisted shapes typical for silica biomorphs remained absent. The raspberry-like form of these architectures is similar to fractal entities found during growth of $\mathrm{BaCO}_{3}$ biomorphs at lower $\mathrm{pH},{ }^{14,20}$ and furthermore strongly resembles morphologies produced upon addition of sodium chloride (cf. Figure 8, below). Again, the data indicate that crystallization is terminated at the end of the fractal stage beyond a certain threshold in the calcium content (which is somewhat higher than in the $\mathrm{BaCO}_{3}$ case), and that the dynamic interplay leading to noncrystallographic ultrastructures can no longer be initiated under these conditions.

Increasing the $\mathrm{Ca}^{2+}$ concentration in the mother solution to molar fractions of 0.20 and 0.50 also gave exclusively fractal aggregates, which were smaller (ca. $100 \mu \mathrm{m}$, cf. Figure 4C,D) than those formed at $x_{\mathrm{Ca}}=0.10$ and differed to some extent in terms of their morphology. While precipitates grown at $20 \mathrm{~mol}$ $\% \mathrm{Ca}^{2+}$ were usually reminiscent of four-petalled clover sheets (Figure 4C), those obtained from solutions containing equal amounts of $\mathrm{Sr}^{2+}$ and $\mathrm{Ca}^{2+}$ proved to be perfect spheroids (Figure 4D). Both types of structures again evolved in contact with vessel walls, as is evident from their flat bottom sides (cf. Figure 4C). Close-up views of the texture of the aggregates disclose myriads of nanoscale subunits, either fibrous (Figure $4 \mathrm{~F}$ ) or platy (Figure 4G), thus supporting the notion of extensive fractal branching in mixed $\mathrm{Sr}^{2+} / \mathrm{Ca}^{2+}$ systems at intermediate molar ratios. Finally, at the highest calcium content investigated in this series $\left(x_{\mathrm{Ca}}=0.80\right)$, the observed crystal morphologies (Figure 4E,H) were fundamentally distinct from those seen at lower $\mathrm{Ca}^{2+}$ concentrations and rather resembled architectures found in the reference experiments with neat $\mathrm{CaCl}_{2}$ solutions (Figure $1 \mathrm{I}-\mathrm{K}$ ).

3.2. Crystal Polymorphism and Composition. 3.2.1. EDX Analysis. Aggregates obtained from the experiments at different $\mathrm{Ca}^{2+} / \mathrm{Sr}^{2+} / \mathrm{Ba}^{2+}$ contents were further examined with respect to their elemental composition as well as their crystalline modification and corresponding cell parameters. For this purpose, structures representative for each calcium concentration (according to Figures 3 and 4) were first analyzed by means of EDX spectroscopy. Figure 5 gives a plot of the measured $\mathrm{Ca} / \mathrm{Me}$ ratios (where $\mathrm{Me}$ is the sum over the atom percentages detected for calcium and barium/strontium, i.e., $\mathrm{Me}=$ atom $\% \mathrm{Ca}+$ atom $\% \mathrm{Sr} / \mathrm{Ba})$ as a function of analytical fraction of $\mathrm{Ca}^{2+}$ in solution. The data show the presence of noticeable amounts of $\mathrm{Ca}^{2+}$ in the crystals already at low solution contents, suggesting that added calcium ions are incorporated into the mineralizing carbonate phase forming solid solutions (as verified by XRD, see below). Interestingly, a linear trend with fairly good correlation can be observed up to $x_{\mathrm{Ca}}=0.50$. This means that the amount of $\mathrm{Ca}^{2+}$ included in the lattice of the mixed crystals directly scales with the analytical fraction in the mother liquor, indicating virtually complete miscibility of the distinct cations in the solid solution. Contrarily, at $x_{\mathrm{Ca}}=0.80$, the $\mathrm{Ca} / \mathrm{Me}$ atomic fractions diverge from the linear trend toward higher calcium contents, especially in case of $\mathrm{Ca}^{2+} / \mathrm{Ba}^{2+}$ mixtures, where deviations are already

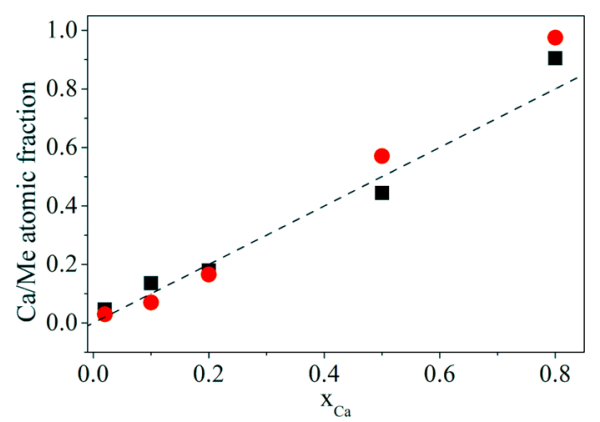

Figure 5. $\mathrm{Ca} / \mathrm{Me}$ atomic ratios determined by EDX spectroscopy for typical aggregates obtained from mixtures of $\mathrm{Ca}^{2+}$ and either $\mathrm{Ba}^{2+}$ (red circles) or $\mathrm{Sr}^{2+}$ (black squares) at different solution compositions. The dashed line represents the case of complete miscibility of calcium and strontium/barium in the resulting crystals (i.e., when the fractions of $\mathrm{Ca}^{2+}$ in the initial solution and in the final solid state are equal). See text for further explanations.

visible at $x_{\mathrm{Ca}}=0.50$. In fact, hardly any barium seems to be incorporated into the forming crystals at $x_{\mathrm{Ca}}=0.80(\mathrm{Ca} / \mathrm{Me}=$ $0.97)$, whereas strontium and calcium still exhibit somewhat higher miscibility at these ratios $(\mathrm{Ca} / \mathrm{Me}=0.90)$. Most likely, this result can be ascribed to smaller differences in the ionic radius between $\mathrm{Sr}^{2+}$ and $\mathrm{Ca}^{2+}(1.45$ vs $1.32 \AA$, coordination number $(\mathrm{CN})=9$ ) as compared to $\mathrm{Ba}^{2+}$ and $\mathrm{Ca}^{2+}$ (1.61 vs 1.32 $\AA$, $\mathrm{CN}=9)$.

The silica content of the aggregates, given as the $\mathrm{Si} / \mathrm{Me}$ atomic ratio, was found to be on the same order of magnitude (generally $<0.10$, in most cases $<0.05$ ) for all of the various fractal structures produced under different conditions (see Table S1 in the SI). The obtained values thus are similar to silica levels reported for the globular clusters occurring during the first stage of morphogenesis in silica-witherite biomorphs. ${ }^{23}$ Since their formation is based on crystal growth poisoning by a non-absorbable impurity (silica), which is constantly pushed ahead by the growing front and not noticeably incorporated, ${ }^{16,41}$ the resulting architectures contain very little silica (as observed). This explains the low count rates for Si in the EDX spectra and furthermore confirms that the distinct spheroidal forms shown in Figures 3 and 4 have been generated by fractal branching at noncrystallographic angles.

3.2.2. X-ray Diffraction. Diffraction patterns recorded from powdered samples (Figure 6) demonstrate that the alkalineearth carbonates crystallize in aragonite-type lattices (virtually phase-pure, no other peaks observed) up to certain molar fractions of $\mathrm{Ca}^{2+}$ in the mother solutions, which differ depending on whether $\mathrm{Sr}^{2+}$ or $\mathrm{Ba}^{2+}$ is used.

In the case of strontium, the forming aggregates favor an orthorhombic phase up to $50 \mathrm{~mol} \% \mathrm{Ca}^{2+}$ (Figure 6A-E), whereas only up to $20 \mathrm{~mol} \%$ can be included into the corresponding witherite/aragonite lattice (Figure $6 \mathrm{H}-\mathrm{K}$ ). Moreover, with increasing calcium content, reflections are shifted toward higher $2 \theta$ values (illustrated for the (111) peak by the red line in Figure $6 \mathrm{~A}-\mathrm{E}$ and $\mathrm{H}-\mathrm{K}$ ) due to the incorporation of the smaller $\mathrm{Ca}^{2+}$ ion into the strontianite/ witherite structure (lattice contraction). This confirms the formation of mixed alkaline-earth carbonate lattices, i.e., solid solutions, in line with the EDX data. To extract the lattice parameters of these mixed crystals, the XRD patterns were further analyzed and fitted by means of the least-squares minimization method. Cell volumes resulting for the distinct calcium molar fractions are plotted in Figure 7. For both 

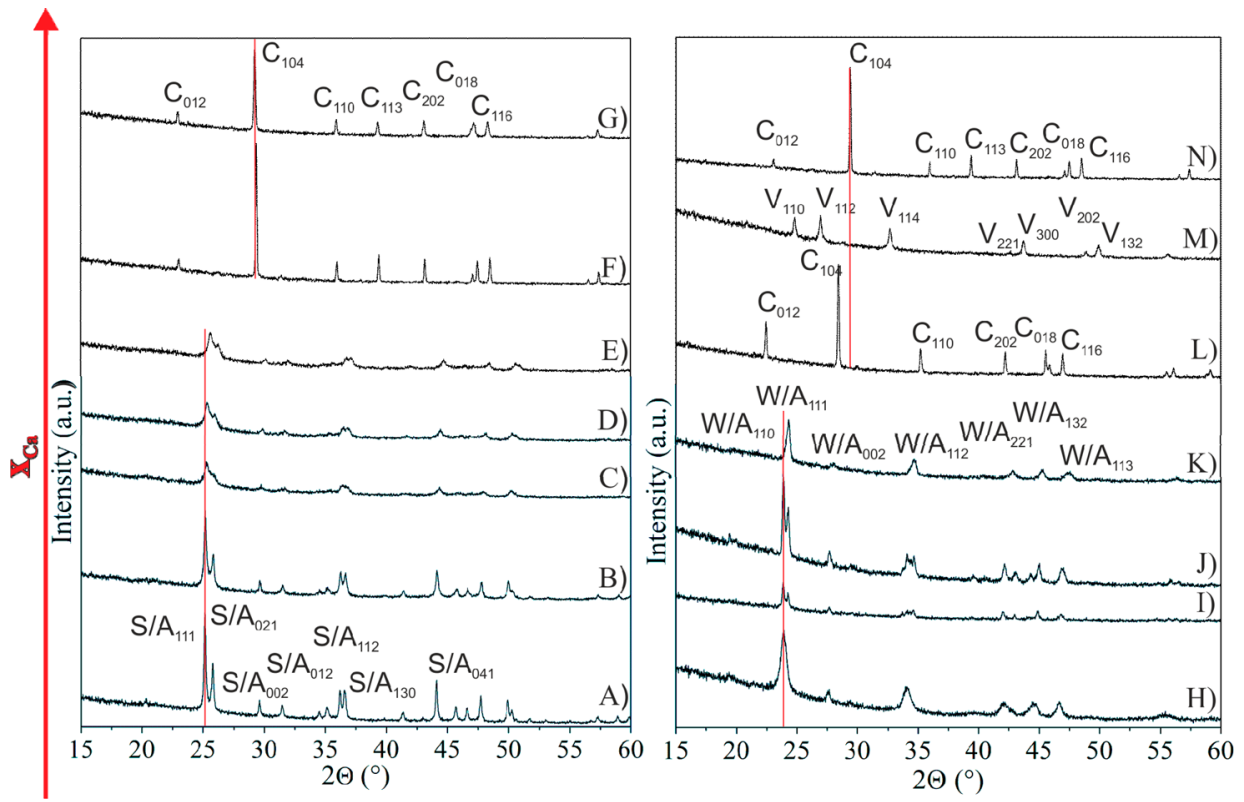

Figure 6. Powder XRD patterns of precipitates isolated after crystallization of alkaline-earth carbonates from dilute silica sols containing different amounts of $\mathrm{Ca}^{2+}$ and either $\mathrm{Sr}^{2+}$ (left) or $\mathrm{Ba}^{2+}$ (right). The molar fraction of $\mathrm{Ca}^{2+}$ ions in the samples was gradually increased as (A,H) 0, (B,I) 0.02, $(\mathrm{C}, \mathrm{J})$ 0.10, (D,K) 0.20, (E,L) 0.50, (F,M) 0.80, and (G,N) 1.00. Notation: C, calcite; V, vaterite; A, aragonite; S, strontianite; W, witherite.

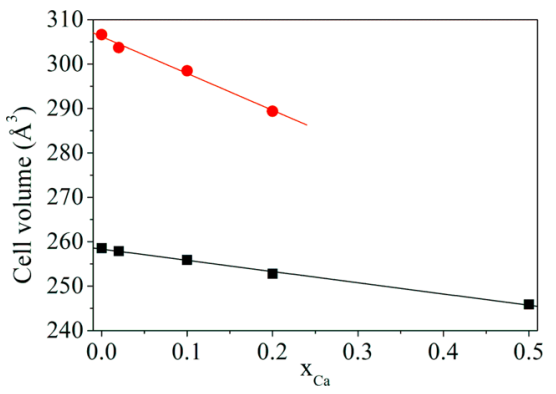

Figure 7. Cell volumes of orthorhombic solid solutions formed upon co-precipitation of $\mathrm{CaCO}_{3}$ and (black squares) $\mathrm{SrCO}_{3}$ or (red circles) $\mathrm{BaCO}_{3}$ from alkaline solutions in the presence of silica and at distinct $\mathrm{Ca}^{2+}$ molar fractions. Values were derived by least-squares minimization of the XRD patterns shown in Figure 6. In both cases, the cell volume decreases linearly as the smaller calcium ions become incorporated into the orthorhombic crystal system. Fits to the data (full lines) give slopes of $-25.25\left(\AA^{3} / x_{\mathrm{Ca}}\right)\left(R^{2}=0.996\right)$ and -82.83 $\left(\AA^{3} / x_{\mathrm{Ca}}\right)\left(R^{2}=0.989\right)$ for $\mathrm{CaCO}_{3} / \mathrm{SrCO}_{3}$ and $\mathrm{CaCO}_{3} / \mathrm{BaCO}_{3}$ solid solutions, respectively.

strontium and barium carbonate, the volume of the unit cell decreases linearly with increasing $x_{\mathrm{C} a}$ as a consequence of the integration of the small $\mathrm{Ca}^{2+}$ cation into the orthorhombic lattice. ${ }^{42}$ Thereby, the decline of the cell volume is obviously much steeper in the case of calcium/barium mixtures, due to the larger difference in the ionic radii of $\mathrm{Ba}^{2+}$ and $\mathrm{Ca}^{2+}$ as already mentioned above, leading to stronger contraction.

When $x_{\mathrm{Ca}}$ is increased to 0.80 in $\mathrm{Ca}^{2+} / \mathrm{Sr}^{2+}$ systems, calcite is the only polymorph, and there are no more reflections of aragonite-type carbonates discernible in the patterns (Figure $6 \mathrm{~F}$ ), in line with the morphological change traced at these $\mathrm{Ca}^{2+}$ fractions (cf. Figure 4D,E). Comparison of the lattice parameters obtained for the particles in the absence of strontium (Figure 6G) and at $x_{\mathrm{Ca}}=0.80$ (Figure 6F) suggests a slight shift in the $a / c$ ratio to lower values (from 0.2923 to 0.2908 ), presumably owing to the inclusion of the larger $\mathrm{Sr}^{2+}$ ions into the rhombohedral lattice, as reflected in the EDX data (ca. 10 atom \% incorporated $\mathrm{Sr}$ ) and also reported in previous studies. $^{37,43-45}$

Similar behavior is observed at $x_{\mathrm{Ca}}=0.50$ for mixtures of $\mathrm{CaCO}_{3}$ and $\mathrm{BaCO}_{3}$ (Figure 6L). However, due to the higher amount of barium in the mother solution, significantly more $\mathrm{Ba}^{2+}$ is incorporated into the calcite structure (up to 43 atom \% according to EDX). This, together with the size of the barium cations, leads to a much more pronounced change of the $a / c$ ratio in this case (from 0.2923 to about 0.2854). Most surprisingly, we find that, for a $\mathrm{Ca}^{2+}$ molar fraction of 0.80 (Figure 6M), vaterite is the exclusive crystalline phase present in the samples. This is clearly unexpected because vaterite is metastable under the given conditions, and calcite was obtained at both lower (Figure 6L) and higher (Figure 6N) calcium content. In order to rule out subtle kinetic effects and issues of sample preparation, this experiment was repeated multiply, each time yielding vaterite as the predominant polymorph. As the EDX data indicate only traces of barium in the crystals (cf. Figure 5), it seems as if $\mathrm{Ba}^{2+}$ - in mixtures with $\mathrm{Ca}^{2+}$ at these particular ratios-is somehow able to stabilize vaterite in solution. Furthermore, it is intriguing to note that the hemispherical structures shown in Figure 3D-F all consist of a different polymorph (aragonite, calcite, and vaterite, respectively), despite their close morphological and textural similarities.

3.3. Effect of Ionic Strength on the Growth Behavior of Silica-Witherite Biomorphs. The above data illustrate that addition of $\mathrm{Ca}^{2+}$ to mother solutions of silica-witherite and silica-strontianite biomorphs can drastically influence the final morphologies. A possible explanation for this behavior is based on specific ion effects, that is, the harder calcium ions interact much more strongly with silicate ions than their softer higher homologues $\mathrm{Sr}^{2+}$ and $\mathrm{Ba}^{2+}$, thereby inducing silica polycondensation via charge screening. In this way, the speciation of silica may be dramatically altered in solution and selfassembly can no longer proceed beyond the initial stage of fractal branching. However, if the main role of added $\mathrm{Ca}^{2+}$ is to 
screen the charges of silicate species and thus facilitate their condensation, then simple electrolytes like sodium chloride should have a similar impact on morphogenesis at sufficiently high concentrations (because the Debye screening length decreases with growing ionic strength). To test this hypothesis, we have performed additional experiments in which attempts were made to grow $\mathrm{BaCO}_{3}$ biomorphs from solutions containing different amounts of excess salt ( $\mathrm{NaCl}$; Figure 8).

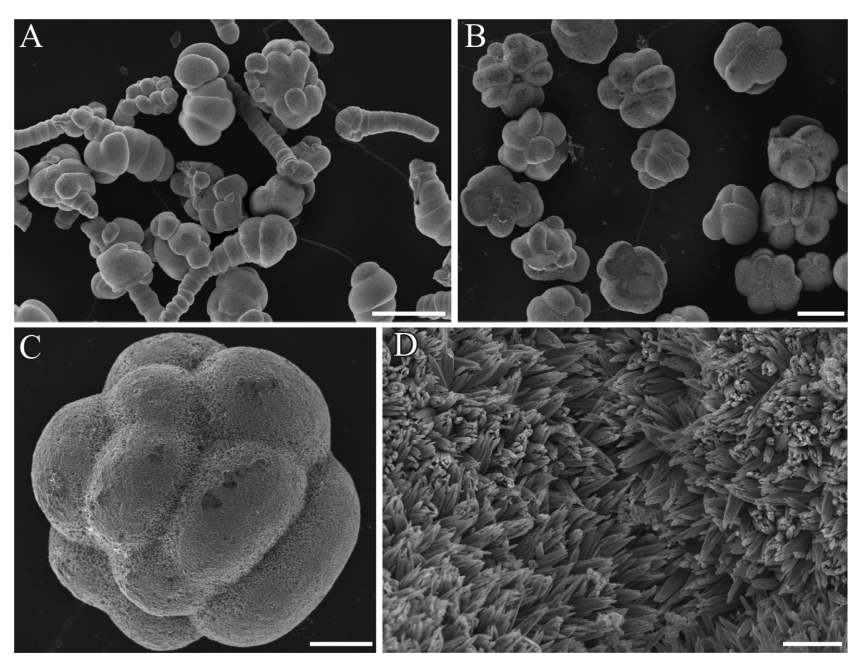

Figure 8. $\mathrm{BaCO}_{3}$ crystal aggregates grown from alkaline silicacontaining solutions, to which (A) 50 and (B-D) $250 \mathrm{mM}$ of excess $\mathrm{NaCl}$ had been added. Scale bars: (A,B) $100 \mu \mathrm{m},(\mathrm{C}) 30 \mu \mathrm{m}$, and (D) $3 \mu \mathrm{m}$.

First distinct effects could be noted at a salt concentration of 50 $\mathrm{mM}$, where no more sheets and helicoids were formed. Instead, globular particles and colony-like clusters of interpenetrating spheroids were observed (Figure 8A).

Frequently, worm-like structures were seen to emerge from these clusters and grow to lengths of often more than $100 \mu \mathrm{m}$. Starting from a $\mathrm{NaCl}$ content of $100 \mathrm{mM}$, even worms were absent and none of the polycrystalline morphologies characteristic of biomorphs remained. Instead, exclusively fractal architectures with diameters around $200 \mu \mathrm{m}$ were found after growth was completed (Figure $8 \mathrm{~B}$ ), typically displaying raspberry-like shapes (Figure $8 \mathrm{C}$ ). As already discussed above, these structures arise from splitting of an initial $\mathrm{BaCO}_{3}$ single crystal and subsequent self-similar ramification, as is evident from close-up views of their surface (Figure 8D), which reveal myriads of nanoscale projections and hence again suggest a large degree of branching. Fractal aggregates with similar raspberry-like morphologies, but smaller dimensions $(\sim 30 \mu \mathrm{m})$, were reported to occur in samples at $\mathrm{pH} 10$ where, likewise, no distinct biomorphic shapes could be generated. ${ }^{14,20,46}$ Thus, excess salt is obviously capable of influencing morphogenesis in a way that is comparable to what has been observed in the presence of $\mathrm{Ca}^{2+}$ ions (cf. Figure 4B), as expected. However, to achieve this, drastically higher concentrations of monovalent ions are required $(100 \mathrm{mM}$ $\mathrm{NaCl}$ vs $0.1 \mathrm{mM} \mathrm{Ca}{ }^{2+}$ ). Under these conditions, the reaction mixtures indeed showed similar turbidity as in the case of the dilute $\mathrm{Ca}^{2+}$-containing solutions, indicating ongoing silica coagulation. This behavior is well-known in the literature and can be ascribed to the bridging ability of divalent cations, ${ }^{39}$ which greatly enhances their coagulation power (that scales with the sixth power of the ion charge according to the
Schulze-Hardy rule ${ }^{47}$ ). EDX analyses of the precipitates do not show significantly increased counts of $\mathrm{Na}$ or $\mathrm{Cl}$ (even at a very high excess of salt), while XRD data confirm the crystalline phase to be pure witherite (see Figure S2 in the SI). These results further corroborate that the added ions do not interact directly with the crystallizing carbonate phase, but rather affect the growth process indirectly by influencing the silica in solution.

\section{DISCUSSION}

4.1. Prevention of Biomorph Formation in the Presence of $\mathrm{Ca}^{2+}$ Ions. The results obtained from experiments with mother solutions containing mixtures of different alkaline-earth cations have shown that the presence of $\mathrm{Ca}^{2+}$ leads to substantial changes during crystallization and prevents the formation of silica biomorphs already at very low concentrations. The most obvious discrepancy between samples with and without added calcium is that the otherwise transparent solutions turn turbid within minutes as soon as $\mathrm{Ca}^{2+}$ is present. The colloidal particles (and polymeric solutes) formed at this stage consist of amorphous silica with minor amounts of entrapped or surface-bound $\mathrm{Ca}^{2+} \cdot{ }^{48}$ With time, these silica colloids sediment toward the bottom of the crystallization wells, where they accumulate and eventually cross-link to build up a layer of silica gel (cf. Figure S1 in the SI), in which growth of carbonates occurs after some delay. These observations demonstrate that calcium ions can catalyze silica polycondensation and coagulation processes by screening repulsive charges much more efficiently than $\mathrm{Sr}^{2+}$ and $\mathrm{Ba}^{2+}$, as reported also in previous work. ${ }^{49-51}$ This can presumably be attributed to the lower charge density of cations with larger size and may be considered a direct manifestation of specific ion effects. ${ }^{52}$

Reinforced condensation in solution will cause the distribution of silicate species to shift toward higher oligomers, long before any carbonate mineralization has commenced. Thus, crystallization will occur under conditions where the actual concentration of silicate monomers and dimers-which likely represent the active species during growth of biomorphs ${ }^{12}$ - is significantly decreased. An apparent consequence of these circumstances is that morphogenesis ceases at the end of the initial fractal route and the system cannot pass into the second stage of chemically coupled co-precipitation and polycrystalline growth. Most probably, this is because considerable amounts of silica were already coagulated independent of carbonate crystallization, so that critical supersaturation levels required for local polymerization and coating of carbonate nanocrystals are no longer accessible. ${ }^{12}$ Therefore, the dynamic $\mathrm{pH}$-based interplay between silica and carbonate-which occurs only within a certain window of bulk conditions ${ }^{14,27}$ - cannot be maintained, rendering concerted self-assembly of complex morphologies impossible. In this regard, direct interactions between $\mathrm{Ca}^{2+}$ and silicate, which can be considered negligible in case of $\mathrm{Sr}^{2+}$ and $\mathrm{Ba}^{2+}$, preclude the formation of biomorphs in these systems.

The notion that enhanced silica condensation prevents growth of curved structures has been confirmed by further experiments in the presence of sodium chloride, used as background electrolyte to vary the ionic strength. Indeed, similar effects were found in terms of the occurring morphologies (i.e., only fractal structures and no more biomorphic shapes); however, drastically higher concentrations of monovalent ions $(\geq 100 \mathrm{mM} \mathrm{NaCl})$ were needed to induce 
changes comparable to those observed for minor contents of divalent $\mathrm{Ca}^{2+}$. Thus, high ionic strengths progressively shield the negative charges of silicate species, thereby favoring their oligomerization $^{39}$ and ultimately resulting in the formation of raspberry-like architectures, instead of biomorphs. A second potential explanation for the distinct growth behavior at elevated salinity refers to the supply of the system with carbonate ions. In fact, large amounts of salt depress the rate of $\mathrm{CO}_{2}$ uptake by the solutions due to a decrease of its solubility in water (which obviously does not apply for experiments with added $\mathrm{Ca}^{2+}$ ions). ${ }^{53}$ In order to trigger and maintain coupled co-precipitation, sufficient bulk concentrations of carbonate species are needed over extended periods of time. This criterion may not be met in media at high ionic strength, and furthermore has proven to be one of the key parameters for the morphological selection at lower $\mathrm{pH}^{14,20}$ In this sense, both the silica and (time-dependent) carbonate speciation seem to be inappropriate for self-assembly in concentrated $\mathrm{NaCl}$ solutions.

In mixtures of calcium and barium, $\mathrm{Ca}^{2+}$ molar fractions as low as 0.02 were sufficient to hinder the formation of biomorphs, lending support to the notion that the cations primarily act in a catalytic way. By contrast, biomorphs were still obtained in $\mathrm{Ca}^{2+} / \mathrm{Sr}^{2+}$ systems at the same composition. In principle, this behavior is counterintuitive, as $\mathrm{Sr}^{2+}$ is harder than $\mathrm{Ba}^{2+}$ and thus should more efficiently support $\mathrm{Ca}^{2+}$ in provoking silica polycondensation. We can only speculate about possible reasons for this finding, but it seems all the more clear that specific ion effects play an important role in these systems. For example, one may argue that the competition of the distinct cations for interaction sites at the silica is the decisive factor in this context. That is, $\mathrm{Sr}^{2+}$ is more readily capable of displacing $\mathrm{Ca}^{2+}$ at silicate groups than $\mathrm{Ba}^{2+}$, thus decreasing the overall tendency for coagulation. In other words, the barium cations leave all interaction potential open to $\mathrm{Ca}^{2+}$, whereas $\mathrm{Sr}^{2+}$ behaves as a true competitor. This idea is supported by dynamic light scattering measurements, which demonstrate that cation-induced silica condensation is faster in calcium-barium than in calcium-strontium mixtures (see Figure S3 in the SI). An alternative scenario is based on the fact that, at lower calcium fractions $\left(x_{\mathrm{Ca}} \leq 0.2\right.$, cf. Figure 5), more $\mathrm{Ca}^{2+}$ is incorporated into the lattice of $\mathrm{SrCO}_{3}$ than in $\mathrm{BaCO}_{3}$ (e.g., 1.09 atom \% $\mathrm{Ca}$ in $\mathrm{SrCO}_{3}$ vs 0.51 atom \% Ca in $\mathrm{BaCO}_{3}$ at $\left.x_{\mathrm{Ca}}=0.02\right)$. Consequently, less free calcium ions would then be available in solution for cation-induced silica condensation, allowing biomorphs to grow in $\mathrm{Ca}^{2+} / \mathrm{Sr}^{2+}$ mixtures up to a calcium molar fraction of 0.02 .

Another interesting observation is that added $\mathrm{Ca}^{2+}$ ions retard carbonate crystallization, such that the growth period had to be increased to 3 days (instead of about $12 \mathrm{~h}$ in case of pure witherite and strontianite biomorphs). As already mentioned, the $\mathrm{pH}$ of the solutions and its variations over time did not noticeably change with the calcium content. This implies that the temporal profiles of the actual carbonate concentration should be similar in all systems and, hence, that the free amount of alkaline-earth cations is lower in $\mathrm{Ca}^{2+}$ containing mixtures. These considerations suggest that $\mathrm{Ca}^{2+}$ along with $\mathrm{Sr}^{2+}$ or respectively $\mathrm{Ba}^{2+}$ ions are temporarily bound to (likely polymeric) silicate species or rather the gel matrix deposited on the bottom of the vials. As a result, the supersaturation of the alkaline-earth carbonates may be decreased as compared to the pure systems, leading to longer growth times. We note, however, that the lower bulk supersaturation could as such be an important limiting factor for the ability of biomorphs to form under the particular circumstances, as described in detail in a recent study. ${ }^{14}$ Decelerated crystallization in the presence of $\mathrm{Ca}^{2+}$ could to some extent also be due to differences in the solubility of the orthorhombic alkaline-earth carbonates $\left(\mathrm{p} K_{\mathrm{SP}}=8.34\right.$ for $\mathrm{CaCO}_{3}, 9.27$ for $\mathrm{SrCO}_{3}$, and 8.56 for $\mathrm{BaCO}_{3}$ at $25{ }^{\circ} \mathrm{C}^{54-56}$ Thus, aragonite is more soluble than strontianite and witherite, and might therefore slow down growth rates for mixed crystals at a given level of ion concentrations.

A final aspect that may contribute to the lack of biomorphs already at low $\mathrm{Ca}^{2+}$ fractions is related to the surface energies and structures of the mixed alkaline-earth carbonate crystals. Recently, Aquilano and co-workers proposed that adsorption of silica on $\mathrm{BaCO}_{3}$ nanoparticles (and hence their stabilization) is promoted by epitaxial matching of silicate chains on the carbonate surfaces, which was demonstrated for witherite on $\alpha$ quartz and inferred for the inverse case. ${ }^{34,57}$ Silica adsorption was suggested to reduce the interfacial tension of the carbonate particles and consequently increase nucleation rates, which was considered to be crucial for the formation of biomorphs. Inclusion of $\mathrm{Ca}^{2+}$ into the witherite (and strontianite) lattice could possibly impair the above-mentioned epitaxial matching and therefore, the nucleation rate of mixed carbonate crystals may not be high enough to sustain the growth of biomorphs.

4.2. Fractal Branching at Different $\mathrm{Ca}^{2+} / \mathrm{Sr}^{2+}$ and $\mathrm{Ca}^{2+} /$ $\mathrm{Ba}^{2+}$ Ratios. Apart from the fact that biomorphs cannot grow already in the presence of minor amounts of $\mathrm{Ca}^{2+}$, our data further demonstrate that various fractal structures are generated over a wide range of compositions. At low calcium contents $\left(x_{\mathrm{Ca}} \leq 0.02\right.$ for $\mathrm{Ba}$ and $x_{\mathrm{Ca}} \leq 0.1$ for $\left.\mathrm{Sr}\right)$, these branched architectures are widely identical to those produced in the absence of $\mathrm{Ca}^{2+}$ and typically adopt either dumbbell-like or spherulitic shapes (cf. Figure 2). In many cases, several of these fractal spheroids bundle to build networks (Figure 3A), or grow together yielding architectures with raspberry- or cauliflowerlike appearance (Figure 3B and Figure 8). However, a commonality of all these forms is that they arise from a seed crystal, which was nucleated heterogeneously with its long axis parallel to the underlying substrate, as is evident from corresponding bottom views (cf. Figure 2). In fact, nucleation appears to occur on the lateral faces of the pseudohexagonal rod, that is, on either (011) or (020). Splitting at both ends and subsequent bifurcation then inevitably results in dumbbell-like intermediates, which later may be closed to give (notched) spheres. These circumstances are illustrated schematically in Figure $9 \mathrm{~A}-\mathrm{C}$. Above a certain threshold in the molar fraction of $\mathrm{Ca}^{2+}\left(x_{\mathrm{Ca}} \geq 0.1\right.$ for $\mathrm{Ba}$ and $x_{\mathrm{Ca}} \geq 0.2$ for $\left.\mathrm{Sr}\right)$, the morphological variety of the observed fractal patterns becomes strongly restricted. Essentially, most of the precipitates display (more or less perfect) hemispherical shapes (cf. Figure 3B-F and Figure 4C,D) and microstructures that are characterized by numerous nanometric projections arranged radially outward from the center of the hemisphere (cf. Figure 3G-I and Figure $4 \mathrm{~F}, \mathrm{G})$. In this context, the crystals produced from $\mathrm{Ca}^{2+} / \mathrm{Ba}^{2+}$ mixtures at $x_{\mathrm{Ca}}=0.10$ (Figure $3 \mathrm{~B}, \mathrm{C}$ ) are an exception, because they are hardly branched and rather consist of partially intergrown micrometer-sized subunits, for reasons that shall not be further discussed here. The formation of hemispherical structures at higher calcium content can be understood when inspecting the flat bottom sides of the aggregates, which were in contact with an interface during both nucleation and growth. In corresponding images (especially Figure 3D), the seed crystal 


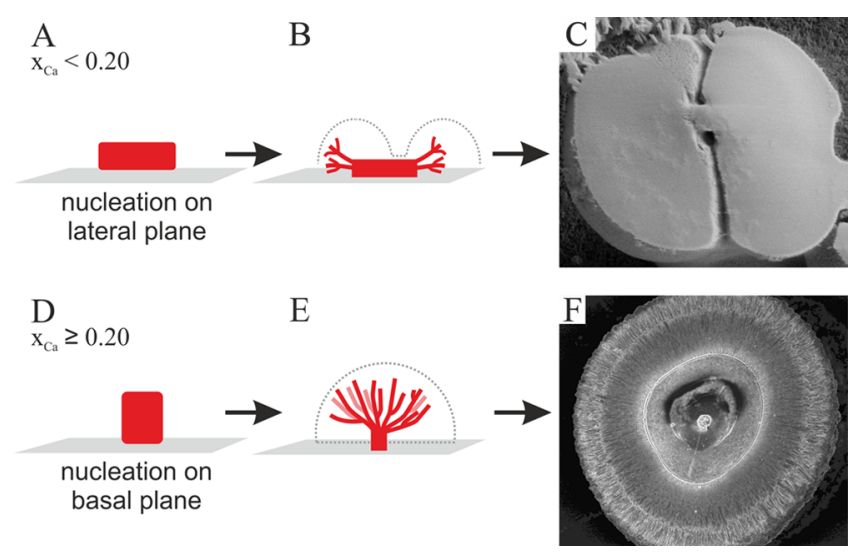

Figure 9. Schematic representation of the fractal growth mechanisms envisaged for lower $(\mathrm{A}-\mathrm{C})$ and higher $(\mathrm{D}-\mathrm{F})$ calcium fractions. Note that structures are not drawn to scale.

located in the core of the hemispheres is seen in cross-section rather than in longitudinal section with respect to the $c$-axis, suggesting that the heterogeneous nucleation behavior differs from that found at lower $\mathrm{Ca}^{2+}$ fractions. In particular, the core crystal seems to have nucleated on the substrate via its basal (001) faces, as visualized in Figure 9D-F.

Self-similar ramification during the following stages of growth leads to hemispherical entities as indicated in Figure 9E, whereas no dumbbell-like intermediates are observed under these circumstances. A possible reasoning for this change in the nucleation behavior is that incorporation of $\mathrm{Ca}^{2+}$ into the mineral phases (as detected by EDX and XRD, cf. Figures 5-7) alters the relative surface energies of the different crystallographic faces, rendering nucleation through (001) favorable over (011) and (020). This might also explain why the transition from the distinct fractals found with no or little added $\mathrm{Ca}^{2+}$ to the hemispheres occurs at higher calcium contents in $\mathrm{Ca}^{2+} / \mathrm{Sr}^{2+}$ mixtures than in $\mathrm{Ca}^{2+} / \mathrm{Ba}^{2+}$ systems, since changes in the structure and surface energies (with respect to the pure phases) are expected to be greater when incorporating calcium in the lattice of witherite $\left(\mathrm{Ba}^{2+}\right.$ being larger than $\left.\mathrm{Sr}^{2+}\right)$.

4.3. Polymorph Selection in Calcium-Strontium and Calcium-Barium Mixtures. Finally, the polymorphism of the aggregates obtained under the various investigated conditions remains to be discussed. In agreement with previous studies, ${ }^{58}$ we find that the alkaline-earth carbonates form orthorhombic solid solutions with virtually complete miscibility of phases over a wide range of compositions $\left(0-20\right.$ and $0-50 \mathrm{~mol} \% \mathrm{Ca}^{2+}$ for $\mathrm{BaCO}_{3}$ and $\mathrm{SrCO}_{3}$, respectively). Accordingly, the unit cell volume of the resulting crystals decreases linearly with increasing calcium content due to progressive lattice contraction (cf. Figure 7), while the fraction of $\mathrm{Ca}^{2+}$ in the solid state directly correlates with that in the mother solution (Figure 5). In strontium-containing systems, a switch in polymorphism is observed only at an excess of calcium $\left(x_{\mathrm{Ca}}=0.80\right)$, where calcite proved to be the only crystalline modification generated. A shift in the corresponding XRD peak positions toward lower angles (Figure 6F,G) indicates significant incorporation of $\mathrm{Sr}^{2+}$ into the rhombohedral lattice, which was determined to be ca. 10 atom \% (Figure 5) and thus about half of the initial solution content. Consequently, $\mathrm{Sr}^{2+}$ integration into calcite is not as favorable as $\mathrm{Ca}^{2+}$ substitution into strontianite, a result that is in line with the literature, where $\mathrm{Sr}^{2+}$ was found to substitute $\mathrm{Ca}^{2+}$ in calcite merely to minor degrees. ${ }^{43,45,59-61}$ In the case of
$\mathrm{Ca}^{2+} / \mathrm{Ba}^{2+}$ mixtures, the situation is more complicated. First, it can be noted that mixed orthorhombic phases occur only up to $20 \mathrm{~mol} \% \mathrm{Ca}^{2+}$, presumably because of the larger difference in cation size and greater structural mismatch. At $x_{\mathrm{Ca}}=0.50$, the forming crystals therefore prefer a calcitic modification (cf. Figure 6L), into which $\mathrm{Ba}^{2+}$ ions are included in fractions as high as 0.43 . This challenges values reported in earlier work, which were considerably lower. ${ }^{45,60,62,63}$ Indeed, partition coefficients determined for $\mathrm{Sr}^{2+}$ and $\mathrm{Ba}^{2+}$ in calcite based on the present experiments $\left(D_{\mathrm{S}, \text {, calcite }}=0.48\right.$ at $x_{\mathrm{Ca}}=0.80$ and $D_{\mathrm{Ba}, \text { calcite }}=0.86$ at $\left.x_{\mathrm{Ca}}=0.50\right)$ exceed those obtained previously by factors ranging from 5 to $45(D \approx 0.03-0.08$ and $0.02-0.03$ for $\mathrm{Sr}^{2+}$ and $\mathrm{Ba}^{2+}$, respectively, in calcite). ${ }^{64,66}$ Although we cannot explain this unexpected discrepancy, one may speculate that the presence of silica in the mother solutions could somehow promote incorporation of the larger alkaline-earth cations into calcite.

Increasing the $\mathrm{Ca}^{2+}$ molar content to 0.80 in calcium-barium systems led to the-likewise unexpected-observation of vaterite being the exclusive crystalline phase detected (Figure 6M). EDX analyses of these crystals have shown that they include only traces of barium (ca. 0.5 atom \%). This complies well with data reported by Brecevic et al., who concluded that absorption of $\mathrm{Ba}^{2+}$ into the vaterite lattice causes distortion (due to larger cation radius) and therefore is strongly limited. ${ }^{66,67}$ However, these low amounts of foreign ions appear to be effective in stabilizing vaterite against energetically favored transformation to calcite, possibly in cooperation with the silicate species in solution.

Last but not least, it is remarkable that the gradual changes in polymorphism, traced when raising the calcium content in mixtures with barium from 0.2 over 0.5 to 0.8 , are not at all reflected in the resulting morphologies and structures, given that hemispheres of similar sizes were formed at all three compositions (Figure 3D-F) and also the constituting nanoscale subunits looked widely identical (cf. Figure 3G-I). Nonetheless, as outlined above, these architectures can obviously consist of any of the three anhydrous polymorphs of calcium carbonate, i.e., aragonite $\left(x_{\mathrm{Ca}}=0.20\right)$, calcite $\left(x_{\mathrm{Ca}}=\right.$ $0.50)$, and vaterite $\left(x_{\mathrm{Ca}}=0.80\right)$. This is of particular interest when considering that these aggregates are supposedly generated by progressive branching of an initial core crystal, and that the habit of this seed crystal should be different for the three polymorphs (rod for aragonite, rhombohedron for calcite, and presumably sphere for vaterite). Current studies are therefore focused on investigating the early stages of crystallization in these systems and elucidating the nature of the core crystal formed by the distinct phases.

\section{CONCLUSIONS}

In this work, we have studied the crystallization of alkalineearth metal carbonates from silica-containing solutions at high $\mathrm{pH}$, gradually replacing $\mathrm{Ba}^{2+}$ or respectively $\mathrm{Sr}^{2+}$ by $\mathrm{Ca}^{2+}$ in mixtures of the corresponding chloride salts. Our results clearly demonstrate that even minor amounts of calcium ions can strongly interfere with the growth behavior otherwise observed for witherite and strontianite under the influence of silica in the absence of $\mathrm{Ca}^{2+}$. In particular, the formation of complex curved morphologies is fully prevented as soon as a certain threshold in the calcium molar fraction is exceeded ( $\geq 2$ and $10 \mathrm{~mol} \%$ for mixtures with strontium and barium, respectively). These findings are mainly ascribed to strong interactions between the "hard" $\mathrm{Ca}^{2+}$ ions and the primary structuring agent in solution, 
i.e., dissolved silicate species. Charge screening by the cations catalyzes silica polycondensation, shifting its speciation toward higher oligomers and eventually inducing coagulation. This leads to circumstances where the chemistry and/or concentration of the relevant components in solution are no longer suitable for dynamically coupled co-mineralization to be initiated. In this regard, it seems as if the failure to produce calcium carbonate-based silica biomorphs at ambient conditions is not solely due to crystal polymorphism (i.e., because $\mathrm{CaCO}_{3}$ favors calcite over aragonite) but also-and probably for the most part-originates from specific ion effects related to the different polarity of the alkaline-earth cations, which govern their competition for interaction with the silica in solution. This notion is supported by the observation that mixed $\mathrm{CaCO}_{3} /$ $\mathrm{SrCO}_{3}$ and $\mathrm{CaCO}_{3} / \mathrm{BaCO}_{3}$ particles, as obtained over a wide range of metal ion ratios, did not assemble into biomorphic ultrastructures (unlike corresponding mixtures of $\mathrm{SrCO}_{3}$ and $\mathrm{BaCO}_{3}{ }^{9}$ ), even when their crystal phase was confirmed to be an orthorhombic aragonite-type solid solution. Thus, the only conceivable way to enable true bottom-up self-organization of $\mathrm{CaCO}_{3}$ biomorphs (no seeding or the like) from dilute sols at room temperature-as observed for both $\mathrm{SrCO}_{3}$ and $\mathrm{BaCO}_{3}-$ would be to deliberately avoid or reduce ionic interactions between $\mathrm{Ca}^{2+}$ and silicate ions in solution, which, in our opinion, is practically impossible.

Instead of complex sinuous morphologies, co-precipitation of the alkaline-earth carbonates and silica afforded a wealth of different fractal structures, all of which contained the distinct metal cations in ratios corresponding more or less to those prevailing in the mother liquor (complete miscibility for orthorhombic solid solutions, lower partitioning of $\mathrm{Sr}^{2+}$ and $\mathrm{Ba}^{2+}$ into vaterite and calcite). Further parameters such as the degree of fractal branching, the detailed size and shape of both the subunits and the entire aggregates, or the crystal orientation during heterogeneous nucleation at interfaces were shown to vary in a subtle manner as depending on the amount of $\mathrm{Ca}^{2+}$ present. Concerning the polymorphism of the architectures, we found that aragonite-type mixed phases prevail in samples at an excess of the larger strontium or barium ions, whereas $\mathrm{Sr}^{2+}$ / $\mathrm{Ba}^{2+}$-substituted calcite was obtained at high $\mathrm{Ca}^{2+}$ fractions, both being widely in line with previous studies. An interesting peculiarity is the formation of pure vaterite in the presence of $\mathrm{Ba}^{2+}$ under particular conditions (i.e., at a $\mathrm{Ca} / \mathrm{Ba}$ ratio of $4: 1$ ), which may or may not be induced by a cooperative stabilization of this actually metastable polymorph by barium ions and silicate species. In any case, our experiments have demonstrated that virtually identical structures (micrometer-sized hemispheres consisting of uniform fibrous subunits) can be generated on the basis of either of the three anhydrous polymorphs of calcium carbonate, simply by adjusting the $\mathrm{Ba}^{2+}$ content in the mother solutions. This, together with the abovementioned variations in the nucleation and growth behavior of the resulting bifurcated entities, highlights that silica-controlled crystallization of alkaline-earth carbonates is not only capable of yielding complex curved forms like biomorphs (even though they are certainly the most prominent example in this context), but can also lead to fractal aggregates with great diversity in terms of morphology, structure, and composition.

\section{ASSOCIATED CONTENT}

\section{S Supporting Information}

Photographs of the samples (Figure S1), EDX data of $\mathrm{Ca} / \mathrm{Sr}$ and $\mathrm{Ca} / \mathrm{Ba}$ crystal aggregates (Table $\mathrm{S} 1$ ), EDX and XRD data of structures grown at high ionic strength (Figure S2), and DLS data of silica polycondensation in $\mathrm{Ca} / \mathrm{Sr}$ and $\mathrm{Ca} / \mathrm{Ba}$ mixtures (Figure S3). This material is available free of charge via the Internet at http://pubs.acs.org.

\section{AUTHOR INFORMATION}

\section{Corresponding Author}

*E-mail: matthias.kellermeier@basf.com. Phone: +49 (0)621 60 43388. Fax: +49 (0)6216643388.

\section{Present Address}

${ }^{\perp}$ M.K.: BASF SE, Material Physics, GMC/O - G201, 67056 Ludwigshafen, Germany

\section{Notes}

The authors declare no competing financial interest.

\section{ACKNOWLEDGMENTS}

The authors thank Prof. JuanMa Garcia-Ruiz (LEC Granada) for valuable discussions. We are further grateful to Prof. Dr. Ralf Witzgall and Dr. Reinhard Rachel (Institute of Microbiology and Archaeal Center, University of Regensburg) for access to their scanning electron microscope and help with the analyses, and to Dr. Martina Andratschke (Institute for Inorganic Chemistry, University of Regensburg) for recording the XRD patterns.

\section{REFERENCES}

(1) Zhang, S. Nat. Biotechnol. 2003, 21, 1172.

(2) Shimomura, S.; Sawadaishi, T. Curr. Opin. Colloid Interface Sci. 2001, 6, 11

(3) Chen, X.; Lenhert, S.; Hirtz, M.; Lu, N.; Fuchs, H.; Chi, L. Acc. Chem. Res. 2007, 40, 493.

(4) Prashant, K. Nanosci. Res. Lett. 2010, 5, 1367.

(5) Hyde, S. T.; Carnerup, A. M.; Larsson, A. K.; Christy, A. G.; Garcia-Ruiz, J. M. Physica A 2004, 339, 24.

(6) Kellermeier, M.; Eiblmeier, J.; Melero-Garcia, E.; Pretzl, M.; Fery, A.; Kunz, W. Cryst. Growth Des. 2012, 12, 3647.

(7) Hyde, S. T.; Garcia-Ruiz, J. M. Actual. Chim. 2004, 275, 4.

(8) Terada, T.; Yamabi, S.; Imai, H. J. Cryst. Growth 2003, 253, 435.

(9) Garcia-Ruiz, J. M.; Amoros, J. L. J. Cryst. Growth 1981, 55, 379.

(10) Garcia-Ruiz, J. M. J. Cryst. Growth 1985, 73, 251.

(11) Garcia-Ruiz, J. M.; Hyde, S. T.; Carnerup, A. M.; Christy, A. G.; Van Kranendonk, M. J.; Welham, N. J. Science 2003, 302, 1194.

(12) Kellermeier, M.; Melero-Garcia, E.; Kunz, W.; Garcia-Ruiz, J. M. J. Colloid Interface Sci. 2012, 380, 1.

(13) Garcia-Ruiz, J. M.; Melero-Garcia, E.; Hyde, S. T. Science 2009, $323,362$.

(14) Eiblmeier, J.; Kellermeier, M.; Rengstl, D.; Garcia-Ruiz, J. M.; Kunz, W. CrystEngComm 2013, 15, 43.

(15) Voinescu, A. E.; Kellermeier, M.; Carnerup, A. M.; Larsson, A. K.; Touraud, D.; Hyde, S. T.; Kunz, W. J. Cryst. Growth 2007, 306, 152.

(16) Kellermeier, M.; Cölfen, H.; Garcia-Ruiz, J. M. Eur. J. Inorg. Chem. 2013, 32, 5123.

(17) Kellermeier, M.; Melero-Garcia, E.; Glaab, F.; Klein, R.; Drechsler, M.; Rachel, R.; Garcia-Ruiz, J. M.; Kunz, W. J. Am. Chem. Soc. 2010, 132, 17859.

(18) Bittarello, E.; Aquilano, D. Eur. J. Mineral. 2007, 19, 345.

(19) Noorduin, W. L.; Grinthal, A.; Mahadevan, L.; Aizenberg, J. Science 2013, 340, 832.

(20) Garcia-Ruiz, J. M. Geology 1998, 26, 843.

(21) Voinescu, A. E.; Kellermeier, M.; Bartel, B.; Carnerup, A. M.; Larsson, A. K.; Touraud, D.; Kunz, W.; Kienle, L.; Pfitzner, A.; Hyde, S. T. Cryst. Growth Des. 2008, 8, 1515.

(22) Kunz, W.; Kellermeier, M. Science 2009, 323, 344. 
(23) Kellermeier, M.; Melero-Garcia, E.; Glaab, F.; Eiblmeier, J.; Kienle, L.; Rachel, R.; Kunz, W.; Garcia-Ruiz, J. M. Chem.-Eur. J. 2012, 18, 2272.

(24) Busch, S.; Dolhaine, H.; DuChesne, A.; M Heinz, S.; Hochrein, O.; Laeri, F.; Podebrad, O.; Vietze, U.; Weiland, T.; Kniep, R. Eur. J. Inorg. Chem. 1999, 1999, 1643.

(25) Busch, S.; Schwarz, U.; Kniep, R. Adv. Funct. Mater. 2003, 13, 189.

(26) Simon, P.; Rosseeva, E.; Buder, J.; Carrillo-Cabrera, W.; Kniep, R. Adv. Funct. Mater. 2009, 19, 3596.

(27) Melero-Garcia, E.; Santisteban-Bailon, R.; Garcia-Ruiz, J. M. Cryst. Growth Des. 2009, 9, 4730.

(28) Kellermeier, M.; Glaab, D.; Carnerup, A. M.; Drechsler, M.; Gossler, B.; Hyde, S. T.; Kunz, W. J. Cryst. Growth 2009, 311, 2530.

(29) Kellermeier, M.; Melero-Garcia, E.; Kunz, W.; Garcia-Ruiz, J. M. Adv. Chem. Phys. 2012, 151, 277.

(30) Dominguez-Bella, S.; Garcia-Ruiz, J. M. J. Cryst. Growth 1986, 79, 236.

(31) Imai, H.; Terada, T.; Yamabi, S. Chem. Commun. 2003, 484.

(32) Imai, H.; Terada, T.; Miura, T.; Yamabi, S. J. Cryst. Growth 2002, 244, 200.

(33) Gower, L. B. Chem. Rev. 2008, 108, 4551.

(34) Bittarello, E.; Massaro, F. R.; Aquilano, D. J. Cryst. Growth 2010, $312,402$.

(35) Lea, D. W.; Shen, G. T.; Boyle, A. Nature 1989, 340, 373.

(36) Alia, J. M.; Diaz de Mera, Y.; Edwards, H. G. M.; GonzalezMartin, P.; Lopez-Andres, S. Spectrochim. Acta, Part A 1997, 53, 2347.

(37) Chang, L. L. Y.; Howie, R. A.; Zussman, J. Non-Silicates: Sulphates, Carbonates, Phosphates and Halides; The Geological Society: London, 1998.

(38) Wray, J. L.; Daniels, F. J. Am. Chem. Soc. 1957, 79, 2031.

(39) Iler, R. K. The Chemistry of Silica. Solubility, Polymerization, Colloid and Surface Properties, and Biochemistry; John Wiley \& Sons: New York, 1979.

(40) Sannon, R. D. Acta Crystallogr. A 1976, 32, 751.

(41) Keith, H. D.; Padden, F. J. Appl. Phys. 1963, 34, 2409.

(42) Lucas-Girot, A.; Hernandez, O.; Oudadesse, H. Mater. Res. Bull. 2007, 42, 1061.

(43) Raitzsch, M.; Duenas-Bohorquez, A.; Reichart, G. J.; de Nooijer, L. J.; Bickert, T. Biogeosciences 2010, 7, 869.

(44) Gebrehiwet, T. A.; Redden, G. D.; Fujita, Y.; Beig, S.; Smith, W. Geochem. Trans. 2012, 13, 1.

(45) Terakado, Y.; Taniguchi, M. Geochem. J. 2006, 40, 161.

(46) Baird, T.; Braterman, P. S.; Chen, P.; Garcia-Ruiz, J. M.; Peacock, R. D.; Reid, A. Mater. Res. Bull. 1992, 2627, 1031.

(47) Evans, D. E.; Wennerström, H. The Colloidal Domain: Where Physics, Chemistry, Biology, and Technology Meet; John Wiley \& Sons: New York, 1999.

(48) Kellermeier, M.; Gebauer, D.; Melero-Garcia, E.; Drechsler, M.; Talmon, Y.; Kienle, L.; Cölfen, H.; Garcia-Ruiz, J. M.; Kunz, W. Adv. Funct. Mater. 2012, 22, 4301.

(49) Marshall, W. L.; Warakomski, J. M. Geochim. Cosmochim. Acta 1980, 44, 915

(50) Zerrouk, R.; Foissy, A.; Mercier, E.; Chevallier, Y.; Morawski, J. C. J. Colloid Interface Sci. 1990, 139, 20.

(51) Iler, R. K. J. Colloid Interface Sci. 1975, 53, 476.

(52) Kunz, W. Specific Ion Effects; World Scientific Publishing: Singapore, 2009.

(53) Zeebe, R. E.; Wolf-Gladrow, D. $\mathrm{CO}_{2}$ in Seawater: Equilibrium, Kinetics, Isotopes; Elsevier: Amsterdam, 2001; Vol. 65, p 346.

(54) Busenberg, E.; Plummer, L. N. Geochim. Cosmochim. Acta 1986, 50, 2225.

(55) Plummer, L. N.; Busenberg, E. Geochim. Cosmochim. Acta 1982, 46, 1011.

(56) Busenberg, E.; Plummer, L. N. Geochim. Cosmochim. Acta 1984, $48,2021$.

(57) Bittarello, E.; Massaro, F. R.; Rubbo, M.; Costa, E.; Aquilano, D. Cryst. Growth Des. 2009, 9, 97.
(58) Holland, H. D.; Borcsik, M.; Munoz, J.; Oxburgh, U. M. Geochim. Cosmochim. Acta 1963, 27, 957.

(59) Pignitore, N. E.; Eastman, M. P. Geochim. Cosmochim. Acta 1986, 50, 2195.

(60) Tesoriero, A. J.; Pankow, J. F. Geochim. Cosmochim. Acta 1995, 60, 1053.

(61) Tang, J.; Köhler, S. J.; Dietzel, M. Geochim. Cosmochim. Acta 2008, 72, 3718.

(62) Pignitore, N. E.; Eastman, M. P. Chem. Geol. 1984, 45, 113.

(63) Gillikin, D. P.; Dehairs, F.; Lorrain, A.; Steenmanns, D.; Baeyens, W.; Andre, L. Geochim. Cosmochim. Acta 2006, 70, 395.

(64) Yoshida, Y.; Yoshikawa, H.; Nakanishi, T. Geochem. J. 2008, 42, 304.

(65) Malone, M. J.; Baker, P. A. J. Sediment. Res. 1999, 69, 216.

(66) Brecevic, L.; Noethig-Laslo, V.; Kralj, D.; Popovic, S. J. Chem. Soc., Faraday Trans. 1996, 92, 1017.

(67) Noethig-Laslo, V.; Brecevic, L. J. Chem. Soc., Faraday Trans. 1998, 94, 2005. 